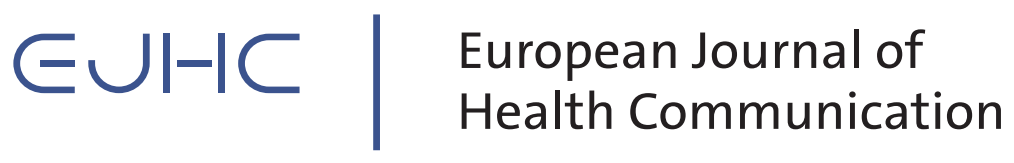

ISSN 2673-5903

ejhc.org

\title{
Sensible Use(rs) and the Construction of Self-Identity in Research \\ Interviews
}

\section{A Qualitative Exploration of how Middle-Aged and Older Adults Search for and Use Online Health Information}

\author{
Martijn Huisman (D), Eduard Cuelenaere (D), Stijn Joye (D), Daniël Biltereyst \\ Department of Communication Sciences, Ghent University, Belgium
}

\begin{abstract}
As a much-used data collection method in qualitative research, interviewing is a primary way to make sense of social life. However, critics point out that interviews are often used uncritically and unreflectively, without considering epistemological foundations and self-presentation efforts by interviewees. By way of a two-step, theory-driven qualitative thematic analysis, this study examines how Belgian middle-aged and older adults (51-79 years old) construct their selfidentity in research interviews as sensible internet users with regards to online health information $(\mathrm{OHI})$ and their motivations for doing so. The findings are underpinned by a theoretical framework which enhances impression management (IM) theory with the thirdperson effect (TPE). The study finds that respondents engage in various IM behaviours, including instances of the TPE, to maximise positive impressions and minimise negative impressions. Through IM, interviewees 1) respond to critical questions; 2) proactively demonstrate knowledge, accomplishments, and positive outcomes; 3 ) compare and distance oneself from others; and 4) communicate limitations and offer external explanations. The findings contribute to the scant literature on IM in research interviews and among older adults and carry various implications for the field of health communication and beyond, such as the importance of critically reflecting on interviewing and going beyond the face value of the data.
\end{abstract}




\section{Keywords}

Online health information, self-identity, impression management, third-person effect, middleaged, older adults, Belgium.

Around the year 1600, William Shakespeare wrote in his play "As You Like It" the famous words: "All the world's a stage, and all the men and women merely players. They have their exits and their entrances, and one man in his time plays many parts." One such part might be played in interviews, which allow individuals not only to express themselves, but also to manage their selfidentity and how others perceive them (Donovan et al., 2014; Schlenker, 2011). As a much-used qualitative method of data collection (Donovan et al., 2014; Mann, 2016), interviews allow researchers to learn about people and their behaviours, beliefs, and views (Atkinson \& Silverman, 1997; Gubrium \& Holstein, 2012; Mann, 2016). In health communication research, qualitative interviews are a common and useful method to elicit the experiences, perceptions, and opinions of respondents with regards to health and health information (Donovan et al., 2014). Interviewing has thus become a primary means of making sense of social life (Gubrium \& Holstein, 2012), to the extent that critics have coined the term 'interview society' (Atkinson \& Silverman, 1997; Mann, 2016), which critiques the widespread and unreflective use of interviews to obtain data without considering their epistemological foundations (Atkinson \& Silverman, 1997; Gubrium \& Holstein, 2012; Hammersley, 2003).

While an exhaustive discussion of methodological criticism of interviewing is beyond the scope of the current contribution ${ }^{1}$, critical voices point out that interviews should be carefully and critically considered as information sources on peoples' nature, experiences, and behaviours (Gubrium \& Holstein, 2012; Hammersley, 2003). Rather than objective or straightforward conversations in which respondents share accounts of their 'realities' or 'truths', interviewer and interviewee engage in the co-construction of meaning and sense-making, as happens in all social interactions (Atkinson \& Silverman, 1997; Hammersley, 2003). Among others, the format and setting of the interview, the nature of the interaction between its participants, as well as the order and form of questions can steer interviewees' responses (Ellis et al., 2002; Franz et al., 2018; Gubrium \& Holstein, 2012; Mann, 2016). Interviews are therefore not only a source of information about phenomena in the life-world of respondents "but also an instance of communication in its own right, shaped by the particularities of the interviewer, the interviewee, the context for their interaction, and so on" (Donovan et al., 2014, p. 24).

A main criticism of interviewing is rooted in notions of social desirability and self-presentation (Hammersley, 2003; Schlenker, 2011), as "participants co-construct meaning, perform identity, and weave stories" (Donovan et al., 2014, p. 26). Self-presentation is a universal and fundamental aspect of social life, as it is human nature to make impressions on others and construct, manage, and protect desired identities (DuBrin, 2011; Schlenker, 2011). By answering questions, interviewees not only make sense of their experiences and attitudes, but they also engage in selfpresentation and performing identities (Donovan et al., 2014). Interviewees might, for instance, talk about themselves in certain ways to appear favourable, give socially desirable answers, or select specific experiences from their past while leaving out others (Donovan et al., 2014; Ellis et al., 2002; Schlenker, 2011). In the context of health communication research, Donovan et al. 
(2014) note that qualitative interviews are "occasions for performing health narratives and identities" (p. 26). In this light, Nettleton et al. (2005) found that interview participants routinely employed 'rhetorical devices' to present themselves as responsible internet users making sensible use of online health information (OHI). Last, as interviews are a form of self-report, (socially) desirable answers as well as recall effects have to be considered (Donovan et al., 2014), as interviewees remember and reconstruct past experiences from memory and narrate these to suit their goals (Schlenker, 2011). The authenticity and accuracy of retrospective narratives of beliefs and behaviours by interviewees has therefore been questioned (Atkinson \& Silverman, 1997).

In the present work, we take a reflective perspective on 31 qualitative, in-depth interviews which we conducted with Flemish middle-aged and older adults between the ages of 51 and 79 about their use of OHI. By way of a supplementary or supra analysis (Heaton, 2004) of our primary qualitative dataset ${ }^{2}$, we examine how these middle-aged and older adults construct their selfidentity and present themselves in the context of searching for and using OHI, as well as their motivations for doing so. The topic of $\mathrm{OHI}$ is of specific relevance to middle-aged and older adults. Given that they likely will be increasingly confronted with (chronic) health issues, middle-aged and older adults stand to potentially benefit from OHI (Huisman et al., 2019). However, OHI is also associated with issues of quality and reliability as well as with negative outcomes such as selfdiagnosis and self-treatment (Huisman et al., 2019; Tan \& Goonawardene, 2017). Furthermore, as they had to learn how to use computers and the internet later in life rather than growing up with them, older adults might be less skilled in using the internet efficiently and properly for OHI purposes. Given that competence and self-reliance are key self-presentation concerns of older adults (Martin et al., 2000), it is therefore of particular interest to explore how middle-aged and older adults construct and present themselves as internet users and OHI seekers. This study is therefore guided by the following research question:

$R Q 1$ : How do respondents construct their self-identity and present themselves with regards to searching for and using online health information?

To answer this question, a two-step, qualitative theory-driven thematic analysis (Boyatzis, 1998) was conducted to both inductively and deductively analyse the interviews and understand interviewees' self-presentation efforts and their meaning. To interpret the interviews and bolster the analysis and findings - and keeping the study's thematic focus 'online health information' (OHI) in mind - we draw from (health) communication, media and psychology studies, and more specifically from the literature on impression management (IM). While IM is the main theoretical lens through which we approach the data, we also employ the third-person effect (TPE) as an enhancement and extension to IM. Additionally, these theories will contextualise our empirical analysis as the study and its research design are inherently explorative of nature: firstly, very few studies have looked at the topic of IM in research interviews, even less so when it comes to health information and communication. Secondly, in an inductive and open manner, the findings emerged during the process of data processing, coding, and analysis rather than being the original intention of the empirical inquiry, further underwriting the study's explorative nature.

The present study is particularly interesting for health communication researchers who plan to use interviews in their study but who wish to a priori critically engage with their findings. It will be shown that OHI should be understood as an equally sensitive and personal subject matter as 
health itself. Taking into account that $\mathrm{OHI}$ can have real consequences, researchers should beware of possibly biased findings because of both social desirability and IM. Therefore, in what follows, the epistemological foundations of the method of the interview itself will be considered, while also reflecting on the underlying social dynamics of the interview as a social and highly rhetorical event where meaning is co-constructed and filtered through both the performance of identities and the relationship between the interviewer and interviewee.

\section{Literature Review}

\section{Impression Management}

In his seminal work The Presentation of Self in Everyday Life (1959), sociologist Ervin Goffman laid out the foundations of studying impression management. Goffman compared people to actors who are continuously engaged, both consciously and unconsciously, in making others believe the impressions and images they create and project of themselves (DuBrin, 2011; Franz et al., 2018). IM refers to how individuals create, adjust, maintain, protect, and monitor the impressions other people form of them in social interactions (Bolino et al., 2008; Ellis et al., 2002; Franz et al., 2018; Martin et al., 2000; Schlenker, 1980, 2011). These impressions might be about the self (e.g., behaviour, beliefs, motivations) as well as personal attributes such as competence and trustworthiness (DuBrin, 2011; Gioaba \& Krings, 2017; Tedeschi \& Riess, 1981; Uziel, 2010). People employ IM for various reasons, such as increasing self-esteem, gaining social approval, giving socially desirable answers, as well as escaping blame and disapproval (i.e., negative perceptions) by minimising weak points (DuBrin, 2011; Ellis et al., 2002; Tedeschi \& Riess, 1981). In the context of OHI, internet users might, for instance, employ IM to appear skilled, careful, and responsible rather than indiscriminate and careless to avoid disapproval. Individuals might employ a variety of verbal and nonverbal IM tactics to maximise favourable impressions (offensive IM) or minimise negative impressions (defensive IM) (Bolino et al., 2008; Franz et al., 2018; Gioaba \& Krings, 2017; Uziel, 2010). All in all, IM substantially affects personal well-being as well as interpersonal behaviour, also in interview settings (Uziel, 2010).

\section{Impression Management in Interviews}

Studies of IM examine dyadic social interactions (Bolino et al., 2008). Thus, while issues of selfpresentation and socially desirable answers might be inherent to all self-report research methods, IM theory is only applied to one-on-one research methods like interviews. Interview settings offer abundant chances to employ IM, particularly in recruitment and evaluation interviews when interviewees are motivated to present themselves favourably (DuBrin, 2011; Gioaba \& Krings, 2017; Uziel, 2010). However, few studies have attempted to investigate IM in research interviews (Bolino et al., 2008; Franz et al., 2018). The scarce literature suggests that research participants (knowing that their beliefs, experiences, and views are the researchers' focus) might engage in IM to leave favourable impressions or to help or impress the interviewer (Franz et al., 2018). 


\section{Impression Management by Older Adults}

The literature suggests that IM is as common among older adults as it is among younger generations (Martin et al., 2000; Ray, 1988), with some studies reporting that older individuals are in fact more eager to present themselves favourably and improve their self-image than younger people and more often provide socially desirable answers (Dijkstra et al., 2001; Fastame \& Penna, 2012; Ray, 1988; Uziel, 2010). Based on a review of gerontology literature, Martin et al. (2000) conclude that, "Like everyone else, older people are attuned to the impressions others may have of them and they are motivated to convey certain desired impressions of themselves" (p. 169). Older adults might furthermore employ IM to counter and refute negative stereotypes related to ageing, such as being inactive or incompetent (Dijkstra et al., 2001; Fastame \& Penna, 2012; Martin et al., 2000; Ray, 1988).

Martin et al. (2000) report that the self-presentation concerns of older individuals centre around physical appearance, behavioural norms, and competence and self-reliance. Regardless of age, people value competence and self-reliance because they tend to lead to, or even reinforce, positive impressions others have of them (Martin et al., 2000; Schlenker, 1980). Being able to effectively use information and communication technologies (ICTs) is obviously an important contemporary competence. To appear ICT competent, older adults might, for example, engage in IM to communicate and emphasise their abilities and accomplishments in using the internet (Bolino et al., 2008; Franz et al., 2018; Gioaba \& Krings, 2017; Schlenker, 2011). In the context of the present study, they might do so to present themselves as having the skills and competencies to obtain credible online health information (OHI). Given the general pervasiveness of self-presentation efforts as part of human nature, we expect that study participants will employ IM to present themselves as responsible and sensible internet users with regards to searching for and using OHI.

\section{Online Health Information}

Many people reflexively search online for health(-related) and medical information (Huisman et al., 2019; Johnson \& Case, 2012; Tan \& Goonawardene, 2017). While consulting OHI might lead to individuals using healthcare services more appropriately and efficiently (Tan \& Goonawardene, 2017), OHI can also lead to anxiety, confusion, and false expectations if information is incorrect, incomplete, or not applicable (Huisman et al., 2019; Tan \& Goonawardene, 2017). Concerns have frequently been raised about the quality of $\mathrm{OHI}$, as well as the skills and level of literacy required to assess the credibility and personal relevance of OHI (Huisman et al., 2019; Johnson \& Case, 2012; Tan \& Goonawardene, 2017).

Some of the numerous studies which examine how people search for and select OHI offer thought-provoking and relevant insights for the present work. Eysenbach and Köhler (2002) report that focus group respondents stated that they appraised the credibility of OHI by considering the source of the information, the website's design and ease of use, and whether the website had a "scientific or official touch" (p. 573). However, when the same study participants were later observed searching for OHI, very few appeared to actually check the source of information, nor did they remember which websites they had visited. Nettleton et al. (2005) found that individuals who search for OHI routinely employ "rhetorical devices" or "rhetorics of reliability" to account for their online information behaviour and to position themselves as careful and responsible 
internet users, "using the internet for health in a manner that is legitimate, appropriate and sensible" (p. 984). Nettleton and colleagues point out that these rhetorical devices do not necessarily represent what people actually do when they search for OHI but are rather "linguistic repertoires that people use when accounting for their actions" (p. 979). These repertoires include comparing oneself to others, that is, invariably describing oneself as careful and sensible while others are perceived as engaging with $\mathrm{OHI}$ inappropriately, indiscriminately, and carelessly (Nettleton et al., 2005). Although not addressed by the authors, the interviewees in the study by Nettleton and colleagues appear to have engaged in impression management (IM) to establish themselves as sensible $\mathrm{OHI}$ seekers, in part by assuming that others are affected more by negative effects of $\mathrm{OHI}$ than themselves. The latter is known in the literature as the third-person effect (TPE).

\section{Third-Person Effect}

Introduced by sociologist Walter Phillips Davison in 1983, the TPE hypothesis proposes that people tend to assume that media messages, particularly those deemed harmful, undesirable, and/or of low credibility and quality, have more effect on others than on themselves (Perloff, 2009; Schlenker, 2011; Tal-Or et al., 2009). The TPE stems from personal needs like self-enhancement and preservation of self-esteem (Perloff, 2009; Stavrositu \& Kim, 2014; Tal-Or et al., 2009), and is related to the need to feel in control, which can be achieved by assuming that the self is not or hardly influenced by the media and the information it disseminates (Perloff, 2009). Perloff (2009) points out that admitting to being influenced by the media can be socially undesirable, as it might make people appear as gullible. Instead, "By assuming the self is invulnerable to communication effects while others are naively susceptible, individuals preserve a positive sense of self and reaffirm their belief that they are superior to others." (p. 256).

The TPE has been extensively tested in relation to traditional mass media (Perloff, 2009; TalOr et al., 2009), but few studies have linked it to digital media (Antonopoulos et al., 2015; Stavrositu \& Kim, 2014). Within the context of health, the TPE has been investigated in a handful of studies about health news (Lee \& Park, 2016; Wei et al., 2008), health information on social media (Stavrositu \& Kim, 2014), and the effects of direct-to-consumer (DTC) prescription drug advertising (DeLorme et al., 2006, 2007). The work by DeLorme et al. is particularly instructive. Believing that being influenced by DTC ads was undesirable, their American respondents aged 57 and over tended to underestimate the effect of DTC ads on themselves and overestimate the effects on others. As the TPE is pervasive (Antonopoulos et al., 2015) and the quality and credibility of $\mathrm{OHI}$ is precarious, we expect that our respondents offer similar contrasting perspectives about themselves and others with regards to OHI. They will likely overestimate the influence of OHI on others, while underestimating and/or downplaying its effects on themselves.

\section{Methods}

\section{Sample}

As part of a larger transdisciplinary audience research about health information in relation to ageing $^{3}, 31$ semi-structured face-to-face interviews about health information experiences were 
conducted between April and September 2015 with middle-aged (age category of 50-64 years old) and older adults (65-80 years old) in Flanders, the Dutch-speaking region of Belgium. Purposive sampling was used to prevent sample bias and to ensure a heterogeneous respondent group in terms of age, gender, and education. The study sample included 13 men and 18 women, with the youngest respondent 51 years of age and the oldest 79 (average age: 63 years). Higher (HE: bachelor/master/university degree) and middle-educated (ME: higher secondary) respondents were somewhat overrepresented compared to informants with lower (LE: no degree, primary and lower secondary) educational levels (HE: 38.7\%, ME: 38.7\%, LE: 22.6\%). The sample included both healthy individuals as well as respondents with (chronic) health issues. All interviewees gave written consent which guaranteed confidentiality and agreed to the interview being recorded.

\section{Data Collection}

A topic list was drawn up beforehand to cover a variety of themes and elicit answers about respondents' health information behaviours and experiences. The interview protocol covered: 1) definitions of health, illness, and health information; 2) sources and use of health information; and 3) three concrete health information cases, namely Alzheimer's disease, sleep disorders, and diabetes. Respondents were asked what they knew about these conditions and where they had obtained their knowledge from. Particularly in the latter two parts of the interview participants talked about their $\mathrm{OHI}$ experiences and views on the internet as a source of health information.

\section{Data Analysis}

The coding and qualitative analysis of the interview data was carried out in NVivo 12 and involved a two-step, theory-driven approach. In the first phase, the first author, after multiple readings of the transcripts, inductively identified and open-coded relevant parts of the interviews by way of thematic analysis (Boyatzis, 1998) to generate pertinent themes and sub-themes. After the first analysis step, a literature review was undertaken to contextualise and make sense of the detected themes and sub-themes, which led to the adoption of IM theory and the TPE. In the second, deductive phase of the analysis, the first and second author coded the data with a predefined IM coding framework adopted from Bolino et al. (2008) and Franz et al. (2018). This framework consists of IM behaviours divided into four categories (maximising good, minimising good, maximising bad, minimising bad) which represent the offensive and defensive nature of IM. ${ }^{4}$ Originating in management and workplace studies (Bolino et al., 2008) and later applied to a usability study (Franz et al., 2018), the framework was adapted by the authors to fit the present study. Specifically, the IM behaviours and their definitions were attuned to the OHI theme. The behaviour Nonverbal was removed, as nonverbal expressions were not recorded during the fieldwork. A new behaviour (Comparing) and corresponding definition was added to reflect the TPE. Last, we put the overarching behaviour categories in a more logical order by starting with maximising good and minimising good before moving on to maximising bad and minimising bad. The resulting IM analysis framework is displayed in Table 1. 
Table 1. IM Framework, Adapted from Bolino et al. (2008) and Franz et al. (2018)

\begin{tabular}{|c|c|c|}
\hline Goal & Behaviour & Definition \\
\hline \multirow{12}{*}{$\begin{array}{l}\text { Maximising } \\
\text { good }\end{array}$} & Comparing* & Compare and contrast oneself to others. \\
\hline & Boasting & $\begin{array}{l}\text { Boast about positive } \mathrm{OHI} \text { experiences/using the internet for health } \\
\text { purposes. }\end{array}$ \\
\hline & Demonstrative & Demonstrate knowledge to appear competent or intelligent. \\
\hline & Enhancement & $\begin{array}{l}\text { Claim that positive outcomes for which they are responsible are more } \\
\text { valuable than generally believed. }\end{array}$ \\
\hline & $\begin{array}{l}\text { Exemplification/ } \\
\text { Self-focused IM }\end{array}$ & $\begin{array}{l}\text { Do more or better than is necessary to attempt to appear dedicated; } \\
\text { behave in ways intended to make the individual seen as nice and polite by } \\
\text { acting like a 'model' participant. }\end{array}$ \\
\hline & Favor rendering & Help others or do favours for them. \\
\hline & Illustrative & Focus on things like broad generalisations to appear competent. \\
\hline & Ingratiation & Use flattery and favour rendering to attempt to appear likeable. \\
\hline & Opinion conformity & Speak or behave in ways consistent with the target; form of ingratiation. \\
\hline & $\begin{array}{l}\text { Other- } \\
\text { enhancement/ } \\
\text { Other-focused IM }\end{array}$ & $\begin{array}{l}\text { Behave in ways intended to make the target perceive them as likable or } \\
\text { attractive. }\end{array}$ \\
\hline & $\begin{array}{l}\text { Researcher- } \\
\text { focused IM }\end{array}$ & $\begin{array}{l}\text { Engage in favour rendering, opinion conformity, and other forms of } \\
\text { ingratiation that is targeted toward the researcher. }\end{array}$ \\
\hline & $\begin{array}{l}\text { Self-enhancement/ } \\
\text { Self-promotion }\end{array}$ & $\begin{array}{l}\text { Communicate abilities and accomplishments to attempt to appear } \\
\text { competent. }\end{array}$ \\
\hline $\begin{array}{l}\text { Minimising } \\
\text { good }\end{array}$ & Supplication & $\begin{array}{l}\text { Portray themselves as weak or dependent, try to appear helpless or needy, } \\
\text { advertise incompetence in a particular area or about a particular issue. }\end{array}$ \\
\hline \multirow[t]{4}{*}{$\begin{array}{l}\text { Maximising } \\
\text { bad }\end{array}$} & Blaming & $\begin{array}{l}\text { Blame the researcher to cover up their perceived incompetence; point out } \\
\text { errors made by the researcher. }\end{array}$ \\
\hline & Defamation & Attempt to harm the reputation of the target. \\
\hline & Intimidation & Threaten or harass to attempt to appear dangerous and powerful. \\
\hline & $\begin{array}{l}\text { Intentionally } \\
\text { looking bad }\end{array}$ & Display a bad attitude or broadcast limitations to look bad or incompetent. \\
\hline \multirow{9}{*}{$\begin{array}{l}\text { Minimising } \\
\text { bad }\end{array}$} & Accounts & Provide explanations for a negative event to escape disapproval. \\
\hline & Apologies & $\begin{array}{l}\text { Accept responsibility for a negative event, apologise to the researcher } \\
\text { about a mistake or limitation. }\end{array}$ \\
\hline & Blaring & Minimise their connection with their peer group. \\
\hline & Burying & Conceal their mistakes or limitations. \\
\hline & Demonstrative & $\begin{array}{l}\text { Demonstrate knowledge to cover up a mistake, or to divert attention from } \\
\text { something negative. }\end{array}$ \\
\hline & Excuses & Deny responsibility for negative behaviour or outcomes. \\
\hline & Illustrative & $\begin{array}{l}\text { Focus on things like broad generalisations to cover up a mistake or to } \\
\text { divert attention from something negative. }\end{array}$ \\
\hline & Justifications & $\begin{array}{l}\text { Accept responsibility for action/event and its negative outcomes, but deny } \\
\text { that the consequences are inappropriate, negative, wrong, or untoward in } \\
\text { any other sense. }\end{array}$ \\
\hline & Self-handicapping & an external explanation for poor performance. \\
\hline
\end{tabular}

Note. *Newly added behaviour. 
The first author coded all 31 interviews, the second author coded eight interviews, after which the coding work was compared. While the authors agreed on the majority of codes, some IM behaviours proved somewhat challenging, both because of an overlap between behaviours and because it was not always straightforward to establish why IM was employed. The few coding disagreements were discussed and ultimately resolved by reading the entire interview transcript again to understand the informants' background, the conversation context, and respondents' overall engagement with OHI. As the interviews took place in a pleasant and respectful manner, no IM behaviours were coded in the category 'maximising bad'. Further, some IM behaviours were only coded once or twice. Given their low frequency as well as due to space constraints, we opted to not include these in our results.

In presenting the findings, we start with four main verbal strategies of IM behaviour (Table 2) and subsequently discuss the individual IM behaviours which contribute to them. All quotes below were extracted from the interviews, anonymised, and translated from Dutch into English by the authors.

\section{Results}

Based on the first round of open, inductive coding and the literature review, we expected that respondents would engage in IM to maximise favourable impressions and/or minimise negative impressions. Our deductive data analysis confirms these expectations. Informants engaged both in offensive IM to manage the interviewers' impressions and appear in a favourable light, as well as more defensive IM to protect their self-image and minimise negative impressions. More specifically, respondents employed IM in four different situations, as displayed in Table 2 and discussed in the remainder of this section.

Table 2. Categories of IM Behaviours in the Interview

\begin{tabular}{ll}
\hline Verbal strategies & Corresponding IM behaviours \\
\hline Respond to critical questions about searching, & - Accounts \\
selecting, and appraising OHI. & - Illustrative (Maximising good) \\
& - Illustrative (Minimising bad) \\
& - Justifications \\
- Remonstrate knowledge, abilities, and & - Boasting \\
$\begin{array}{l}\text { accomplishments, communicate positive experiences } \\
\text { and outcomes of OHI. }\end{array}$ & - Demonstrative \\
& - Favour rendering \\
Compare, contrast, and distance oneself from others. & - Blaring \\
& - Comparing \\
Communicate limitations and weakness, provide & - Self-handicapping \\
external explanations for lack of skills. & - Supplication
\end{tabular}




\section{Respond to Critical Questions About Searching, Selecting, and Appraising $\mathrm{OHI}$}

The majority of IM took place when interviewees were confronted with critical questions about how they searched for and selected OHI and assessed its quality, credibility, and relevance. This corresponds with the notion of IM as defensive and avoidance-based self-presentation effort employed not to gain social approval, but to avoid social disapproval (Uziel, 2010). Although many respondents appeared to use the internet indiscriminately and uncritically, others seemed aware that $\mathrm{OHI}$ is linked to credibility and quality issues as well as potential negative outcomes. Given this association, the critical questions by the interviewer, and the expectations that physicians dislike their patients to lookup OHI (Huisman et al., 2019), respondents likely perceived that appearing to use OHI uncritically and at face value might be socially undesirable and negatively reflect on themselves (DeLorme et al., 2007). Specifically, informants employed five types of IM when responding to critical questions, namely providing accounts (explanations), resorting to illustrative statements (broad generalisations and commonplaces about the internet to appear competent and/or divert attention), offering justifications, and engaging in researcherfocused IM.

Accounts. Respondents offered various general explanations for how they dealt with OHI to deflect critical questions and avoid disapproval. First, they stated that they only rarely searched for $\mathrm{OHI}$ (low frequency) and that the duration of looking for OHI was limited. Second, informants explained that they only trusted $\mathrm{OHI}$ to a limited extent.

I will certainly never assume that what it says there is the absolute truth or the only possibility. (Female, 52, ME)

Further, informants explained that they did not bother to check the authorship or sources of OHI as this was too difficult and/or time-consuming. Particularly middle and lower educated respondents appeared to not really bother to assess the quality and credibility of OHI, indicating that they would visit their physician if something were really wrong.

I look at different websites to see if it is a bit the same. But in the end, if something is really wrong, I just go to the doctor. (Female, 62, LE)

Illustrative (Maximising Good \& Minimising Bad). Respondents frequently resorted to broad generalisations and mundane commonplaces about the internet and OHI, seemingly to appear as competent, critical, and responsible internet users.

Of course, the internet is as they say a cloud, you never have 100 percent control over it. It remains anonymous. (Male, 53, HE)

At other times, respondents uttered similar generalisations and vague statements to divert attention from uncritically using the internet for OHI purposes and/or not being able to describe their search and selection process. The following respondent, for instance, stuck to such vague statements when asked how he selected OHI of good quality: 
I am aware that you certainly cannot immediately fathom all of it. We experience a number of things, and that is positive, evolving. Certain things are now being talked about as good, but after some time it appears that is not true. It varies. I try to use a bit of common sense to see what is reasonable and what not. (Male, 60, HE)

Justifications. Respondents not only offered explanations (Accounts) but also justifications. Informants mainly justified searching for OHI by stressing its limited importance for their health management and decision-making processes. More specifically, they stated that they only searched for OHI out of curiosity or to quickly find some basic information. Second, respondents downplayed the role of OHI by pointing to their physician as the medical authority and foremost source of health information.

I do not go to the pharmacist based on information from the internet and ask for this or that. I think that personal contact with my doctors and specialists is much more important than the internet is. (Male, 58, LE)

By extension, respondents implied that a critical evaluation of OHI authorship and sources was not really necessary as they did not act upon OHI (e.g., diagnose or treat themselves) and OHI did not play a role in their decision-making processes.

Researcher-focused IM. Some respondents appeared to engage in opinion conformity and ingratiation towards the interviewer. Given the critical questions, these respondents likely perceived that having a critical attitude towards OHI was socially desirable and favourable in the eyes of the interviewer. Typically, informants who first admitted that they did not look at the sources of $\mathrm{OHI}$ immediately afterwards told the interviewer that they would pay more attention and be more critical of $\mathrm{OHI}$ in the future.

I never thought about that. I just look at whether the explanation is substantiated or something, but... the sources... Now that you ask me this question, I am a little surprised. [...] From now I will be more conscious of it. (Female, 59, HE)

\section{Demonstrate Knowledge, Abilities, and Accomplishments and Communicate Positive Experiences and Outcomes of $\mathrm{OHI}$}

Besides responding to critical questions, respondents also proactively engaged in four types of offensive IM (i.e., maximising good) to demonstrate their knowledge and accomplishments as internet users and information seekers and to communicate positive experiences with OHI. Based on the literature (Franz et al., 2018; Gioaba \& Krings, 2017; Martin et al., 2000) it indeed stands to reason that respondents emphasised their skills in searching for and selecting OHI, and more generally their ICT skills and positive experiences, to counter and refute common perceptions and stereotypes of older adults as non-users or non-proficient users. Additionally, much IM in this category aimed at demonstrating intelligence and a critical outlook, as well as educational and professional achievements. 
Boasting. Particularly higher educated respondents were likely to boast about their positive experiences with OHI. Some looked up health problems and found different explanations and solutions than the ones provided by their physician. The following respondent, for instance, proudly recounted how he learned online that his heel might have been temporarily inflamed, rather than suffering from heel spurs. Against the advice of his physician, he forewent buying special soles.

I told her, "I'm going to wait". After 1.5 years it was gone. Had I followed the doctor I would have bought those soles. It turned out it was not what she had diagnosed. (Male, $68, \mathrm{HE})$

More generally, participants emphasised how the internet was beneficial to them as it helped to save time and money, both by not having to visit the doctor as well as being able to compare prices of over-the-counter medication and supplements.

Demonstrative. One of the most frequent IM behaviours was to demonstrate knowledge to appear competent and/or intelligent. Particularly higher educated respondents were keen to stress their educational background and critical outlook.

I am a man of science. [...] I am critical in all respects. (Male, 68, HE)

Others pointed out their professional experience to appear competent and knowledgeable and indicate that they did not let themselves get carried away by $\mathrm{OHI}$.

You often do not know where information comes from. I am wary of alternative types and quacks. I think that is because of my past, my work, where I heard many stories. I am suspicious of things I read about health on the internet; I will never assume it to be $100 \%$ truth. (Female, 68, ME)

Respondents also exhibited their knowledge of the internet, specifically the need to be critical when searching for and selecting OHI.

You always have to be careful with the internet. Use it with restriction. Not everything is correct. Anyone can write a newsletter or put something on a website. You should not always believe it. (Male, 76, LE)

By stating that the internet should not be trusted blindly but be approached critically, these respondents implicitly communicated that they themselves were critical and therefore rational, sensible users. 
Favour Rendering. Respondents mentioned that helping family members or friends was a positive reason for and outcome of looking up OHI. These informants primarily looked up OHI to understand what others were going through, although some actually passed on information they found online. This respondent, for example, looked up information for her older siblings who did not have internet access:

I have an alcoholic sister. I google for all kinds of info... I think it is good that she reads that, so I print it out and give it to her. We are with five at home and I am the only one who uses the computer. (Female, 55, LE)

Self-enhancement and Self-promotion. Interviewees communicated various abilities and accomplishments to appear competent and sensible OHI seekers. Middle and especially higher educated informants were more likely to state that they looked for scientific and/or specialised sources, which they deemed more credible and trustworthy than other OHI sources.

The thing I look for is whether there is something from a research centre or a university.

Because I think that is more scientifically based. (Male, 60, HE)

Others stressed their awareness of commercial motives. By emphasising their aversion of commercial content and their self-perceived ability to detect and avoid commercially natured $\mathrm{OHI}$ (e.g., advertisements), respondents presented themselves as savvy internet users.

There will always be a bit of suspicion: Who posted this? Is this commercial information? (Male, 65, ME)

By extension, informants stated they would never purchase health(-related) products or medicines online. They were aware of the possible dangers and almost proudly stated they would always avoid companies selling health products online.

I will never buy medication on the internet. [...] It has often been said to stay away from medication. Do not order anything from the internet, the makers themselves do not know what is in it. It is all fake... (Female, 56, ME)

\section{Compare, Contrast, and Distance Oneself from Others}

The third category covers the related IM behaviours Blaring and Comparing and together represent the TPE. Respondents invariably attributed negative effects of OHI (e.g., taking it too far, hypochondriac tendencies, self-diagnosis) to others, but not to themselves. In underwriting the work of DeLorme et al. (2007), we find that respondents compare and contrast themselves to others in two ways. First, they refer to the "general public", "hypochondriac people", or "forum users"; groups of unknown and anonymous (imagined) others, who are generally thought of as uncritical, irresponsible, and gullible. Second, respondents refer more narrowly to people they know such as family members and colleagues. The indiscriminate use of $\mathrm{OHI}$ and hypochondriac tendencies in these people is explained by individual characteristics such as intelligence, education level, as well as specific health contexts (e.g., concerns about disease symptoms). All in all, respondents deemed others to be more vulnerable and at risk from the dangers and negative outcomes of OHI than 
themselves (the TPE). By disassociating themselves from these known and unknown (imagined) others and the pitfalls of $\mathrm{OHI}$, interviewees positioned themselves as responsible online information seekers.

Blaring. Informants minimised the connection with their peer group (others using the internet for health information purposes) most commonly by distancing themselves from people with hypochondriac tendencies and those who self-diagnose based on what they find on the internet.

I am not a hypochondriac always looking for information. No, that is not me. I might take a look sometimes if something is wrong. (Female, 71, LE)

Respondents also distanced themselves from particular OHI sources, namely discussion forums and social media. Especially forums were dismissed as untrustworthy places where people play doctor and give each other unqualified health advice.

Those forums are ridiculous. Sometimes I accidentally click on a link and end up on a forum where people give each other... they play doctor. It is ludicrous. That would be the last place where I would get information from. (Female, 55, LE)

Comparing. In comparing and contrasting themselves with others to stress their careful attitude towards $\mathrm{OHI}$, respondents tended to project negative outcomes of $\mathrm{OHI}$ on others and deny or downplay these effects on themselves, which is a classic example of the TPE. For instance, interviewees recognised that $\mathrm{OHI}$ might lead to hypochondriac thoughts and behaviour. Not so much in themselves, however, but in others. While informants said they guarded themselves against hypochondriac thoughts, they thought others were more likely to expect the worst based on $\mathrm{OHI}$ and give in to hypochondriac thoughts.

People always think the worst. They immediately think they have colon cancer if they have stomach pain. (Female, 68, ME)

Informants also remarked that other people, but not themselves, too easily and quickly turn to the internet to search for OHI, even though it might not be personally relevant. Some thought that $\mathrm{OHI}$ might lead to other people becoming worried, visiting their physician more frequently, and possibly even challenging the doctor and demand extra testing or certain medication.

You start imagining things, go to the doctor, and then it is not what you thought at all. I think that is dangerous... I think a lot of people do that. (Female, 54, HE)

\section{Communicate Limitations and Weakness, Provide External Explanations For Lack of Skills}

In the last category we find Supplication and Self-handicapping, which are respectively aimed at minimising good and minimising bad. Respondents acknowledged that they encountered difficulties when searching for, selecting, and appraising OHI. First and foremost, they stated that they were not able to grasp specialised and scientific sources of health information. Particularly female respondents appeared to recognise the limits of their computer and internet knowledge and 
skills. The literature suggests that acknowledging one's limits can also be a way of managing impressions and a means of constructing self-identity within the boundaries of the interviews. Nettleton et al. (2005) note in this regard that, "Displaying one's limits to knowledge and acknowledging the superior knowledge of 'experts' was a further way of presenting oneself as a rational and sensible person" (p. 986). Thus, respondents disclosing the limits of their knowledge and abilities might also be considered a form of IM in order to appear a rational and sensible internet user.

Self-handicapping. Typically, female respondents explained their lack of critically selecting and appraising OHI by referring to their limited experience with computers and the internet. The stories by these respondents were surprisingly similar and told of how they had not grown up with computers but had learned to use them later in life. Having grown up in pre-digital times they quite often considered ICTs as a necessary evil.

I was not brought up with using a computer. I can send e-mails, I can look up something, but I am not a specialist. It is not my medium. It is a necessary evil for me. (Female, 67, ME)

Supplication. Most commonly, informants mentioned that OHI was too specialistic and/or scientific and full of jargon. Respondents opinionated that they were not qualified to read such information, which should in their opinion be left to physicians and scientists.

There is information that we as ordinary people are not competent to judge. It is more for doctors and scientists than ordinary people, who might draw the wrong conclusions. (Female, 77, HE)

Study participants also indicated that, as laypersons, they possessed insufficient knowledge to determine the correctness of OHI. Some stated that they trusted OHI to be correct but recognised that they might be ignorant in doing so.

I do not think they will say things which are not medically correct. I mean, maybe I am naive. (Male, 79, LE)

Last, several respondents indicated that they experienced difficulties finding OHI with the help of search engines, wondering if they had enough experience to find what they were looking for.

There is not that much information on Google, I think. Maybe I cannot find it because I do not have enough experience with search engines. (Male, 67, ME)

\section{Education and IM}

In addition to the four overarching aspects of IM discussed above, interesting differences were observed between respondents in terms of education level. Higher educated respondents and, to a lesser extent, middle educated respondents displayed a larger variety of IM behaviours and in a higher frequency compared to lower educated respondents. More specifically, higher educated informants were more occupied with foregrounding and emphasising their educational and professional background, intelligence, and critical stance towards the internet in general and OHI 
in particular. They were also more likely to boast of their positive experiences with OHI. Middle and lower educated respondents on the other hand were more likely to uncritically use the internet for $\mathrm{OHI}$ purposes, which they justified by emphasising the limited role of $\mathrm{OHI}$ and relying on their physician in case of health problems. These findings somewhat contrast with the scarce literature on IM in relation to education level. In their study of socially desirable answers by Dutch older adults aged 65 and over, Dijkstra et al. (2001) found that education was negatively correlated with IM. That is, higher educated respondents were found to engage less in IM and provide less socially desirable answers. While the authors hypothesised that higher educated people might have a more critical attitude and are able to 'see through' questions and thus engage less in IM, the study was in fact inconclusive as for the reasons why higher educated respondents made less efforts to present themselves in favourable ways. The literature review by Uziel (2010) concludes that the few studies which investigate IM in relation to education level report a mildly negative correlation at best and usually no significant correlation. Thus, in contrast to the quantitative (review) studies by Dijkstra et al. (2001) and Uziel (2010), herein we find, based on a qualitative analysis, that higher and, to a lesser extent, middle-educated respondents engage more in IM than informants with lower education levels. Clearly, more research on this topic is necessary, particularly with regards to older adults.

\section{Discussion and Conclusion}

In this contribution, we examined 31 qualitative research interviews with Flemish middle-aged and older adults (51-79 years old) on the topic of online health information (OHI) by way of a supplementary/supra qualitative analysis (Heaton, 2004). A theoretical framework was introduced which expanded impression management theory with the third-person effect to explore how research participants construct their self-identity and present themselves with regards to using the internet for $\mathrm{OHI}$ purposes. Corroborating the literature on IM in other types of interviews (Bolino et al., 2008; Franz et al., 2018) as well as the argument that older individuals are more likely to engage in IM (Dijkstra et al., 2001; Martin et al., 2000; Ray, 1988; Uziel, 2010), 13 offensive and defensive IM behaviours were detected in the interviews. These IM behaviours were part of four overarching verbal strategies, namely to 1) respond to critical questions about searching, selecting, and appraising $\mathrm{OHI} ; 2$ ) demonstrate knowledge, abilities, and accomplishments and communicate positive experiences and outcomes of $\mathrm{OHI}$; 3) compare, contrast, and distance oneself from others; and 4) communicate limitations and weaknesses and provide external explanations for a lack of skills. All in all, engaging in IM helped respondents to present themselves within the context and structure of the interviews as rational internet users making sensible use of the web to find, obtain, appraise, and use OHI. Thus, the present findings echo the work of Nettleton et al. (2005) who found that interviewees routinely employed "rhetorical devices" to appear as responsible and sensible OHI users. Furthermore, the findings back the argument by Donovan et al. (2014) that interview participants perform health narratives and identities as they co-construct meaning during the course of the interview. As such, interviews are indeed "not only a window into other phenomena that occur outside the interview, they sometimes constitute the phenomenon we wish to study" (Donovan et al., 2014, p. 26). The findings herein pertaining to respondents' self- 
presentation efforts indeed suggest that attention to the construction of meaning and interviewee identity in interviews can be a productive undertaking. They further demonstrate the relevance of doing so in a context of health communication as such identities encompass specific attitudes and acts in relation to one's health.

Our study and its findings carry various implications for the scholarly field of health communication and beyond. In the first place, the study offers evidence of IM and TPE in a setting (qualitative research interviews), thematic context (health information, specifically OHI) and among a target group (middle-aged and older adults) previously not or hardly studied. The presence of IM is perhaps little surprising, given that it is part of human nature to make impressions on others (Schlenker, 2011). The presence of the TPE is more surprising but corroborates the statement by Antonopoulos et al. (2015) that the TPE "appears on all typical media independently of the method employed, the medium under study, the observed content, the flow of questions, and the phrasing or the quality of the message." (p. 49). From a methodological and theoretical viewpoint, this work thus not only demonstrates the relevance of IM as an analytical lens to reflect on qualitative research interviews, but also contributes insights to the small body of literature and empirical work on IM in (research) interviews.

Secondly, this study has meaning to the field of health communication as the findings herein illustrate not only that $\mathrm{OHI}$ is a rich topic of study ${ }^{5}$ but also that it can be and is a personal, sensitive, and even intimate subject matter like health itself. There is a lot at stake with health information, which, as described in the literature review, can have real-world health outcomes, both positively and negatively. At the same time, the credibility and quality of health information is, certainly on the internet, precarious and questionable (Huisman et al., 2019). The methodological and theoretical reflections and empirical findings herein illustrate that health information in a broad sense and $\mathrm{OHI}$ specifically are interview topics which, fuelled by their interaction with indicators of age and education (Dijkstra et al., 2001; Martin et al., 2000), might lead to socially desirable answers and IM.

Third and last, as an exercise in reflecting on qualitative research interviews (Mann, 2016), this study draws attention to and advocates for health communication researchers to pay attention to the epistemological foundations of interviewing and go beyond the face value of the data. That is, to consider and reflect on the nature of the interview as both a method to obtain research data as well as a social event in which interviewer and interviewee engage in the co-construction of meaning and sense-making and interviewees perform identity and engage in IM (Donovan et al., 2014). This contribution points out that health communication researchers should pay attention to the position and role of the interviewee when interviewing people about their health information behaviours and practices. Not just in order to distinguish between 'genuine' and more socially desirable answers, but also to come to richer insights and findings pertaining to those information behaviours.

To conclude, the present explorative work might inspire and/or help other (health communication) researchers to consider and anticipate IM behaviour in their interviews. After all, it is in our human nature to present and enhance ourselves to others to our best interests, also or perhaps particularly in research interviews. For we are and continue to be merely players, who have their entrances and exits and play their part on the stage that is the world and everyday life. 


\section{Limitations}

The presented findings should naturally be considered in light of the study's inherent limitations. First, this contribution is the result of a supplementary/supra analysis (Heaton, 2004), as the research of which this study is part of was not originally carried out to examine self-presentation efforts by respondents and analyse these through the lens of IM and the TPE. Rather, this way of reflectively looking at the data emerged during data processing, coding, and analysis. Future work might attempt to reproduce our findings by explicitly approaching the interviews as sites of selfpresentation and design the fieldwork to test for IM and the TPE.

Second, it was sometimes challenging to 'read between the lines' and code interview transcripts for IM behaviour, since respondent statements can be interpreted in multiple ways and some IM behaviours are interrelated and/or overlap. Here, the literature unfortunately does not offer much help, for the few studies examining IM in research settings are hardly transparent when it comes to their analytical procedures (Franz et al., 2018). Taking Goffman's (1959) argument that people perform IM in all social interactions as their starting point, Franz et al. (2018) considered all participant statements as IM and coded them accordingly, although they recognised that with this approach, they might have interpreted genuine sentiments as IM. In the present work, we used a somewhat more targeted approach, first by selecting only the relevant parts of the interviews pertaining to $\mathrm{OHI}$, and subsequently coding the respondent statements with the use of the analysis framework. Nonetheless, it is possible that we also coded genuine statements as IM, which appears, at least for now, to be somewhat inherent to this kind of explorative research.

All in all, however, our two-step theory-driven analytical approach, as well as having two authors code interviews and compare the coding work, surely contributed to the robustness of the analysis and the quality and validity of the findings. Third, given its origins in workplace and usability studies, respectively, the IM analysis framework to code the data did not always prove a perfect fit. Following the literature review, we therefore had to adapt the framework to match the OHI context of our study. Fourth, while IM behaviour can be both of a verbal and nonverbal nature, nonverbal expressions were unfortunately not recorded in the transcripts, which is why they were not included in the study. Further, no IM behaviours were coded in the category 'maximising bad', while other categories were left out of this work given that they were only coded once or twice in total. Future research, in different settings and with different participants, might show that these IM behaviours do occur in research interviews. Fifth and last, because of the qualitative, explorative character of this contribution, we did not include quantitative measures such as frequency of IM behaviours in the analysis. We therefore cannot, for instance, rank IM behaviours in terms of frequency of occurrence. 


\section{Notes}

1. For critical discussions on interviewing, see Atkinson \& Silverman (1997), Donovan et al. (2014), Gubrium \& Holstein (2012), Hammersley (2003), and Mann (2016).

2. As the most common type of secondary analysis, supplementary analysis refers to examining in more depth a theme or subset of the data which emerges as a post hoc matter of interest and which was not or only partially addressed by the primary research (Heaton, 2004). Supra analysis is a form of secondary analysis in which "the terms of the primary study from which the data were derived are transcended. Such studies involve the investigation of new theoretical, empirical or methodological questions" (Heaton, 2004, p. 39). The present contribution emerged as a topic of interest to the research team during and after the fieldwork (i.e., during the first readings and open coding of the interviews) rather than being the intention and original focus.

3. Ghent University GOA-project BOF14/GOA/014, "(De)constructing health news: a transdisciplinary investigation into news media coverage of elderly-related health issues", 2014-2018/20 (main supervisor: D. Biltereyst, co-supervisors: P. Bracke, T. Christiaens, G. Jacobs, S. Joye, K. Raeymaeckers).

4. 'Maximising good' refers to maximising favourable impressions, 'minimising good' to the tendency to portray oneself as weak or incompetent to reduce and avoid negative impressions and blame. 'Maximising bad' includes blaming others, intimidation, and intentionally looking bad at something, while 'minimising bad' refers to defensive IM strategies aimed at minimising negative impressions and protecting and/or repairing the individual's image.

5. As evidenced by the large body of literature which has appeared since the late 1990s to study the internet as a source of health information (Huisman et al., 2019; Johnson \& Case, 2012).

\section{Acknowledgements}

The authors thank all respondents who participated in the study and the reviewers and editors for their constructive feedback.

\section{Declaration of Conflicting Interests}

The authors declare that there is no conflict of interest. No ethical issues had to be addressed.

\section{Funding}

This study was supported by the Special Research Fund of Ghent University [Grant BOFGOA 2014000604 “(De)constructing Health News”]. 


\section{References}

Antonopoulos, N., Veglis, A., Gardikiotis, A., Kotsakis, R., \& Kalliris, G. (2015). Web thirdperson effect in structural aspects of the information on media websites. Computers in Human Behavior, 44, 48-58. https://doi.org/10.1016/j.chb.2014.11.022

Atkinson, P., \& Silverman, D. (1997). Kundera's immortality: The interview society and the invention of the self. Qualitative Inquiry, 3(3), 304-325. https://doi.org/10.1177/107780049700300304

Bolino, M. C., Kacmar, K. M., Turnley, W. H., \& Gilstrap, J. B. (2008). A multi-level review of impression management motives and behaviors. Journal of Management, 34(6), 1080-1109. https://doi.org/10.1177/0149206308324325

Boyatzis, R. E. (1998). Transforming qualitative information: Thematic analysis and code development. Sage.

Davison, W. P. (1983). The third-person effect in communication. Public Opinion Quarterly, 47(1), 1-15. https://doi.org/10.1086/268763

DeLorme, D. E., Huh, J., \& Reid, L. N. (2006). Perceived effects of direct-to-consumer (DTC) prescription drug advertising on self and others: A third-person effect study of older consumers. Journal of Advertising, 35(3), 47-65. https://doi.org/10.2753/JOA00913367350304

DeLorme, D. E., Huh, J., \& Reid, L. N. (2007). "Others are influenced, but not me”: Older adults' perceptions of DTC prescription drug advertising effects. Journal of Aging Studies, 21(2), 135-151. https://doi.org/10.1016/j.jaging.2006.06.001

Dijkstra, W., Smit, J. H., \& Comijs, H. C. (2001). Using social desirability scales in research among the elderly. Quality and Quantity, 35(1), 107-115. https://doi.org/10.1023/A:1004816210439

Donovan, E. E., Miller, L. E., \& Goldsmith, D. J. (2014). “Tell me about a time when...”: Studying health communication through in-depth interviews. In B. B. Whaley (Ed.), Research methods in health communication: Principles and application (pp. 21-40). Routledge.

DuBrin, A. J. (2011). Impression management in the workplace: Research, theory, and practice. Routledge.

Ellis, A. P. J., West, B. J., Ryan, A. M., \& DeShon, R. P. (2002). The use of impression management tactics in structured interviews. Journal of Applied Psychology, 87(6), 12001208. https://doi.org/10.1037/0021-9010.87.6.1200

Eysenbach, G., \& Köhler, C. (2002). How do consumers search for and appraise health information on the world wide web? Qualitative study using focus groups, usability tests, and in-depth interviews. British Medical Journal, 324(7337), 573-577. https://doi.org/10.1136/bmj.324.7337.573

Fastame, M. C., \& Penna, M. P. (2012). Does social desirability confound the assessment of selfreported measures of well-being and metacognitive efficiency in young and older adults? Clinical Gerontologist, 35(3), 239-256. https://doi.org/10.1080/07317115.2012.660411

Franz, R. L., Baecker, R., \& Truong, K. N. (2018). "I knew that, I was just testing you": Understanding older adults' impression management tactics during usability studies. $A C M$ Transactions on Accessible Computing (TACCESS), 11(3), 1-23. https://doi.org/10.1145/3226115 
Gioaba, I., \& Krings, F. (2017). Impression management in the job interview: An effective way of mitigating discrimination against older applicants? Frontiers in Psychology, 8. https://doi.org/10.3389/fpsyg.2017.00770

Goffman, E. (1959). The presentation of self in everyday life. Doubleday.

Gubrium, J. F., \& Holstein, J. A. (2012). Narrative practice and the transformation of interview subjectivity. In J. F. Gubrium, J. A. Holstein, A. B. Marvasti, \& K. D. McKinney (Eds.), Handbook of interview research (2nd ed., pp. 27-44). Sage.

Hammersley, M. (2003). Recent radical criticism of interview studies: Any implications for the sociology of education? British Journal of Sociology of Education, 24(1), 119-126. https://doi.org/10.1080/01425690301906

Heaton, J. (2004). Reworking qualitative data. Sage.

Huisman, M., Joye, S., \& Biltereyst, D. (2019). Searching for health: Doctor Google and the shifting dynamics of the middle-aged and older adult patient-physician relationship and interaction. Journal of Aging and Health, 32(9), 998-1007. https://doi.org/10.1177/0898264319873809

Johnson, J. D. \& Case, D. O. (2012). Health information seeking. Peter Lang.

Lee, H., \& Park, S-A. (2016). Third-person effect and pandemic flu: The role of severity, selfefficacy method mentions, and message source. Journal of Health Communication, 21(12), 1244-1250. https://doi.org/10.1080/10810730.2016.1245801

Mann, S. (2016). The research interview: Reflective practice and reflexivity in research processes. Palgrave Macmillan.

Martin, K. A., Leary, M. R., \& Rejeski, W. J. (2000). Self-presentational concerns in older adults: Implications for health and well-being. Basic and Applied Social Psychology, 22(3), 169-179. https://doi.org/10.1207/S15324834BASP2203_5

Nettleton, S., Burrows, R., \& O'Malley, L. (2005). The mundane realities of the everyday lay use of the internet for health, and their consequences for media convergence. Sociology of Health \& Illness, 27(7), 972-992. https://doi.org/10.1111/j.1467-9566.2005.00466.x

Perloff, R. M. (2009). Mass media, social perception, and the third person effect. In J. Bryant \& M. B. Oliver (Eds.), Media effects: Advances in theory and research (3rd ed., pp. 252-268). Routledge.

Ray, J. J. (1988). Lie scales and the elderly. Journal of Personality and Individual Differences, 9(2), 417-418. https://doi.org/10.1016/0191-8869(88)90106-7

Schlenker, B. R. (1980). Impression management: The self-concept, social identity, and interpersonal relations. Brooks/Cole.

Schlenker, B. R. (2011). Self-presentation. In M. R. Leary \& J. P. Tangney (Eds.), Handbook of self and identity (2nd ed., pp. 492-518). Guilford Press.

Stavrositu, C. D., \& Kim, J. (2014). Social media metrics: Third-person perceptions of health information. Computers in Human Behavior, 35, 61-67. https://doi.org/10.1016/j.chb.2014.02.025

Tal-Or, N., Tsfati, Y., \& Gunther, A. C. (2009). The influence of presumed media influence: Origins and implications of the third-person perception. In R. L. Nabi \& M. B. Oliver (Eds.), The SAGE handbook of media processes and effects (pp. 99-112). Sage. 
Tan, S. S., \& Goonawardene, N. (2017). Internet health information seeking and the patientphysician relationship: A systematic review. Journal of Medical Internet Research, 19(1), Article e9. https://doi.org/10.2196/jmir.5729

Tedeschi, J. T., \& Riess, M. (1981). Identities, the phenomenal self, and laboratory research. In J. T. Tedeschi (Ed.), Impression management and social psychological research (pp. 3-22). Academic Press.

Uziel, L. (2010). Rethinking social desirability scales: From impression management to interpersonally oriented self-control. Perspectives on Psychological Science, 5(3), 243-262. https://doi.org/10.1177/1745691610369465

Wei, R., Lo, V. H., \& Lu, H. Y. (2008). Third-person effects of health news: Exploring the relationships among media exposure, presumed media influence, and behavioral intentions. American Behavioral Scientist, 52(2), 261-277. https://doi.org/10.1177/0002764208321355

\section{Author Contributions}

Conceptualisation (main idea, theory): Martijn Huisman, Eduard Cuelenaere

Funding acquisition: Daniël Biltereyst, Stijn Joye

Project administration: Daniël Biltereyst, Stijn Joye

Methodology (design, operationalisation): Martijn Huisman

Data collection: Martijn Huisman, Eduard Cuelenaere

Data analysis: Martijn Huisman, Eduard Cuelenaere

Writing - original draft: Martijn Huisman

Writing - review \& editing: Martijn Huisman, Eduard Cuelenaere, Stijn Joye, Daniël Biltereyst

\section{Author biographies}

Martijn Huisman, $\mathrm{PhD}$ (corresponding author), was formerly attached to the Department of Communication Sciences and the Health, Media \& Society research centre of Ghent University, Belgium. He is currently active in the market research industry within the field of healthcare.

Eduard Cuelenaere is Visiting Professor and Postdoctoral Researcher at the Department of Communication Sciences, Ghent University, Belgium. His research interests are in the fields of film studies and media industry studies with a focus on film serialities.

Stijn Joye is Associate Professor at the Department of Communication Sciences, Ghent University, Belgium. His research interests are in the field of international communication with a focus on mediated suffering.

Daniël Biltereyst is Professor in media studies at the Department of Communication Sciences of Ghent University, Belgium, in addition to being Director of the Centre for Cinema and Media Studies. 